\title{
Linking feeding activity and sediment reworking in the deposit-feeding bivalve Abra ovata with image analysis, laser telemetry, and luminophore tracers
}

\author{
Olivier Maire ${ }^{1, *}$, Jean-Claude Duchêne ${ }^{1}$, Lionel Bigot ${ }^{2}$, Antoine Grémare ${ }^{1}$ \\ ${ }^{1}$ Université Pierre et Marie Curie-Paris 6 and CNRS, UMR7621, 66650 Banyuls-sur-Mer, France \\ ${ }^{2}$ Laboratoire d'Ecologie Marine, ECOMAR, Université de La Réunion, Avenue René Cassin-BP 7151, \\ 97715 Saint Denis Cedex, France
}

\begin{abstract}
The quantitative relationship between activity (as detected by the comparison of grey levels in successive images using automated software) and sediment reworking in the depositfeeding bivalve Abra ovata was investigated based on simultaneous and continuous measurements using laser telemetry, luminophore tracers, and image analysis. Total activity included both feeding (siphoning) and shell and/or foot activity. Sediment reworking was assessed through the measurements of surface sediment handling and vertical sediment mixing during 2 separate experiments. Surface sediment handling correlated positively with surface feeding activity. Shell and/or foot activity induced oscillatory movements of the superficial sediment layer but did not account for true vertical sediment mixing. Conversely, feeding activity induced intense vertical sediment mixing. Quantitative changes in feeding activity and vertical sediment mixing based on a biodiffusion model were positively correlated. These results underscore the importance of considering both the nature and intensity of infaunal activity when parameterizing models of sediment reworking.
\end{abstract}

KEY WORDS: Abra ovata $\cdot$ Sediment reworking $\cdot$ Activity $\cdot$ Micro-topography $\cdot$ Laser telemetry · Luminophores $\cdot$ Biodiffusion $\cdot$ Image analysis

\section{INTRODUCTION}

The water-sediment interface is a key zone for marine biogeochemical cycles, since its functioning largely controls the fate (i.e. resuspension, remineralization, burial) of sedimented organic matter. Sedimentary systems are characterized by a suite of tight and complex associations between physical, chemical, and biological processes operating at different spatial and temporal scales (Waldbusser \& Marinelli 2006), and the biological processes of major interest in this context are locomotion, burrowing, feeding, and bioirrigation. Through these ecological processes, the infauna has an impact on oxygen uptake (Andersen \& Kristensen 1988, Glud et al. 2003), porewater fluxes (Marinelli 1992, 1994), and sediment reworking (Rhoads 1974, Aller 1982). The resulting effects are clearly dependent on the nature and the intensity of infaunal activity (Boudreau \& Marinelli 1994, Gérino et al. 1998, Maire et al. 2006).

Field and laboratory studies have been conducted to link infaunal activity with both porewater transport and sediment reworking (Bianchi 1988, Marinelli 1992, 1994, Lindsay \& Woodin 1996). To our knowledge, these studies were all based on indirect (Bianchi 1988), independent (Lindsay \& Woodin 1995, 1996), or discontinuous (Marinelli 1992, 1994) activity measurements. It is difficult to assess infaunal activity over the same temporal and spatial scales as biogeochemical processes within the sediment column. For example, the assessment of vertical sediment mixing is an indirect measurement arrived at by fitting a model to the vertical profile of a tracer (Boudreau 1986a,b, Boudreau \& Imboden 1987, Meysman et al. 2003). The methodological constraints (e.g. the minimal thickness of an analyzed sediment layer), and the decay kinetics 
of commonly used tracers estimate mixing rates for processes occurring over relatively long periods of time (several weeks) and at relatively large spatial scales (the scales of vertical sectioning of cores, typically $\geq 0.5 \mathrm{~cm}$ ) (Rice 1986, Sharma et al. 1987, Gérino et al. 1998). Infaunal activity per se is also difficult to quantify. It often affects restricted areas and may change over short time scales (typically a few minutes; Grémare et al. 2004). Moreover, a given organism may have different kinds of activity (Grémare et al. 2004) inducing different sediment mixing modes (François et al. 1997, 2001). The occurrence of multiple infaunal activities, each causing different types of sediment mixing with different intensities, combined with marked temporal changes in the intensity of a given activity (Fuller et al. 1988) further complicates the establishment of a quantitative relationship between infaunal activity and sediment mixing rates.

New experimental techniques in sediment profile imaging have recently been introduced to assess vertical sediment mixing (Gilbert et al. 2003, Solan et al. 2004, Maire et al. 2006). These approaches combine luminophore pulses and high resolution image analysis to estimate vertical sediment mixing over short time scales (i.e. a few minutes, Solan et al. 2004, Maire et al. 2006). Similar image analysis techniques also allow continuous quantification of infaunal activity at a high spatial resolution (Duchêne \& Rosenberg 2001, Hollertz \& Duchêne 2001).

Using these techniques, the surface feeding activity of the deposit-feeding bivalve Abra ovata was recently quantified (Grémare et al. 2004). The results showed that the addition of low concentrations of organic matter significantly enhanced the feeding activity of this bivalve. In sediment column experiments using thin aquaria, and the same techniques with Abra ovata, a low organic input also induced a significant increase of vertical sediment mixing (Maire et al. 2006), suggesting a positive relationship between the intensity of feeding activity and vertical sediment mixing. However, these measurements were not made simultaneously, since activity was measured at the sediment surface whereas sediment mixing was measured within the sediment column. A. ovata processes large quantities of surface sediment (A. Grémare pers. obs.), the amounts of which can be quantified by comparing successive micro-topographic mappings based on the projection of a laser line onto the sediment surface (Roy et al. 2002, 2005). This approach, using consecutive micro-topographic maps, could allow a quick assessment of surface sediment handling by A. ovata, thereby facilitating the assessment of the relationship with the surface feeding activity of $A$. ovata.

The objectives of this study were to assess the quantitative relationship between feeding activity and sedi- ment reworking for Abra ovata employing simultaneous and continuous measurements. Sediment reworking (i.e. surface or volume of sediment that has been mixed through bivalve activity) was estimated with separate measurements of both surface sediment handling (sediment volume per time, $\mathrm{mm}^{3} \mathrm{~h}^{-1}$ ) and vertical sediment mixing (sediment surface per time, $\mathrm{cm}^{2} \mathrm{yr}^{-1}$ ). Surface sediment handling was quantified using laser telemetry. Feeding activity and sediment mixing were assessed using recently developed image analyzing techniques (Grémare et al. 2004, Maire et al. 2006).

\section{MATERIALS AND METHODS}

Bivalve collection and maintenance. Abra ovata is a deposit-feeding bivalve that lives buried a few centimeters below the sediment surface and feeds at the watersediment interface using its inhalant siphon (Grémare et al. 2004, Maire et al. 2006). It is generally found in sandy mud in northwest Mediterranean lagoons, where up to several thousand individuals per $\mathrm{m}^{2}$ can be observed (Guelorget \& Mayère 1981). A. ovata specimens were hand-collected in June 2005 at a water depth of $<1 \mathrm{~m}$ on the north side of the Lapalme Lagoon (France). The water temperature was $20^{\circ} \mathrm{C}$ and salinity $30.5 \mathrm{psu}$. Bivalve specimens were kept in lagoon sediment and well-aerated lagoon seawater at the Observatoire Océanologique de Banyuls-sur-Mer (France). Salinity was progressively increased to 37 psu (i.e. the salinity of running seawater in the laboratory, which is within the range of weekly variations in the lagoon during summertime), within $7 \mathrm{~d}$. Bivalves were then kept in flow-through tanks with circulating surface seawater $\left(20^{\circ} \mathrm{C}, 37 \mathrm{psu}\right)$ and lagoon sediment for $2 \mathrm{wk}$ before being used for experiments. They were fed every other day with crushed Tetramin ${ }^{\circledR}$ brand fish food and were starved $48 \mathrm{~h}$ before the beginning of each experiment. The shell length of each specimen used during the study was $13 \mathrm{~mm}$ (corresponding to a mean width of $10 \mathrm{~mm}$ and a mean thickness of $4 \mathrm{~mm}$ ). Two experiments were carried out sequentially. The first experiment determined the relationship between bivalve surface feeding activity and surface sediment handling, and the second assessed the relationship between bivalve feeding activity and vertical sediment mixing.

Surface sediment experiment. Four experimental boxes $(\mathrm{L}=17.5 \mathrm{~cm}, \mathrm{~W}=11.5 \mathrm{~cm}, \mathrm{D}=7.5 \mathrm{~cm})$ were filled with $5 \mathrm{~cm}$ of natural lagoon sediment (median grain diameter: $103 \mu \mathrm{m}$, organic carbon: $4.55 \%$ dry wt, nitrogen: $0.56 \%$ dry wt) previously sieved through a $1 \mathrm{~mm}$ mesh to remove macrofauna, and then stored in a flowthrough tank with surface seawater. After 48 h, these boxes were placed in a larger aquarium with temperature-controlled circulating seawater $\left(20^{\circ} \mathrm{C}, 37 \mathrm{psu}\right)$ and 
a single bivalve was gently deposited at the sediment surface (Fig. 1A). All bivalves used during the study buried within a few minutes.

After a $24 \mathrm{~h}$ acclimation period, bivalve activity and surface sediment handling were recorded for $27 \mathrm{~h}$ under infrared lights. Surface sediment handling rates were measured over a $64 \mathrm{~cm}^{2}(8 \times 8 \mathrm{~cm})$ surface area, since preliminary experiments showed that the surface area of sediment prospected by the inhalant siphon of $13 \mathrm{~mm}$ long bivalves never exceeded $60 \mathrm{~cm}^{2}$ (O. Maire pers. obs.). The micro-topography of the studied sediment area was assessed using a laser telemeter (Sick OD 80-15 N152, frequency $=21.7$ measures $\mathrm{s}^{-1}$, with each measure being the average of 64 data points) fixed on 2 Parker $600 \mathrm{~mm}$ step motor tables, and placed $9 \mathrm{~cm}$ above the sediment surface (Fig. 1A). The horizontal resolution was $200 \mu \mathrm{m}$ (resulting in a matrix of $16 \times 10^{4}$ measurement points covering the observed sediment surface), and the vertical resolution was $15 \mu \mathrm{m}$. Voltages generated by the laser telemeter were converted to distances using a calibration curve established with a series of 20 objects of known sizes standing on a horizontal surface, which resulted in a suitable range of distances between the laser source and the top of each object. An entire scan lasted $67 \mathrm{~min}$. This duration was determined by the characteristics of the laser telemeter (see above) and the size of the surface studied. There

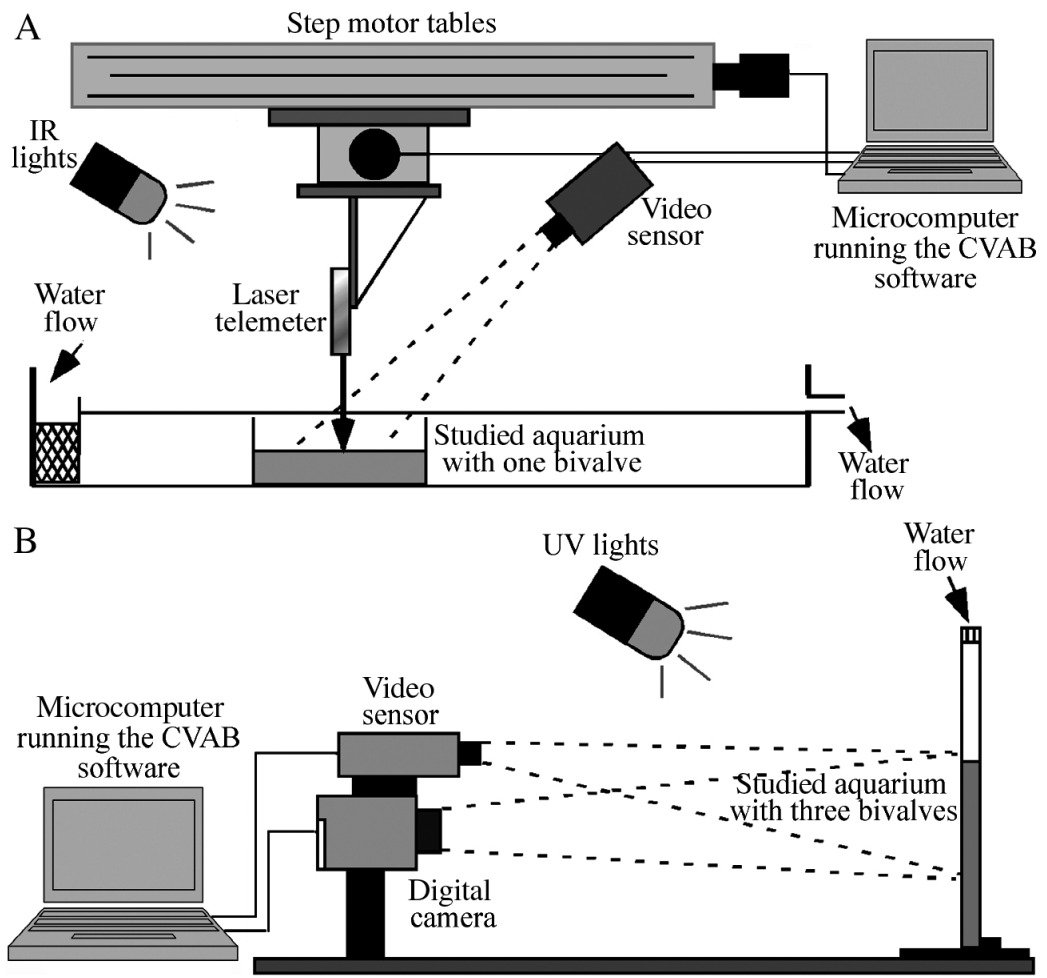

Fig. 1. Experimental setup used during (A) the sediment surface and (B) the sediment column experiments was no time interval between 2 consecutive scans. The bivalve's siphon occasionally interfered with telemetry measurements. These events were easily detected and were discarded and replaced by interpolated values using the 8 neighboring points. Surface sediment handling rates (sediment volume per time) were assessed by summing the absolute values of the differences in micro-topography between 2 consecutive scans divided by the time duration of an entire scan.

Surface feeding activity (i.e. siphon motion) was monitored using an automated image acquisition system composed of a video sensor (VC51, fitted with a $25 \mathrm{~mm}$ objective) connected to a microcomputer and driven by the CVAB software (Grémare et al. 2004). The sensor was fixed $30 \mathrm{~cm}$ above the sediment at an angle of $45^{\circ}$ to avoid interference with the laser telemeter (Fig. 1A). Preliminary trials showed that: (1) the entire studied sediment surface could be in focus using this set up, and (2) perspective distortion resulted in only a slight $(<10 \%)$ underestimation of activity. The frequency of image acquisition was $15 \mathrm{~s}$, which has proven adequate for assessing surfacefeeding activity in Abra ovata (Grémare et al. 2004). Images were saved in JPEG format $(736 \times 568$ pixels $)$ and were afterwards assembled into an AVI film. Image processing was performed using this film with the CVAB software. Surface feeding activity was evaluated using a pixel-by-pixel comparison of grey levels between 2 consecutive images. Modified objects were defined as the sets of adjacent pixels for which the difference between the 2 images was higher than the noise of the captor (i.e. 25 units on a 0 to 255 scale). Differences were then attributed to feeding if the grey levels of modified pixels in the first of the 2 images were between 100 and 170 (on a 0 to 255 scale). Surface feeding activity was then expressed as $\mathrm{cm}^{2}$ of siphon $\mathrm{h}^{-1}$. This procedure accounts for all siphon movements occurring at the water- sediment interface (e.g. even those occurring at the same location multiple times). It was validated by superposing the time series of areas affected by siphon activity and actual video recordings.

The relationships between temporal changes in surface feeding activity and surface sediment handling rates were assessed using simple linear regression models (with surface feeding activity as the independent variable and surface sediment handling rate as the dependent variable). 
Sediment column experiment. Five thin aquaria $(\mathrm{L}=$ $17 \mathrm{~cm}, \mathrm{~W}=1.2 \mathrm{~cm}, \mathrm{D}=33 \mathrm{~cm}$ ) were filled with $15 \mathrm{~cm}$ of lagoon sediment collected at the same time as the bivalves and pre-sieved through a $1 \mathrm{~mm}$ mesh to remove any macrofauna. These aquaria were kept in a thermoregulated room under circulating seawater $\left(20^{\circ} \mathrm{C}, 37 \mathrm{psu}, 1 \mathrm{wk}\right)$. Vertical sediment mixing was quantified using luminophores (Mahaut \& Graf 1987) as described by Maire et al. (2006) (Fig. 1B). Three bivalves were gently deposited on the sediment surface. After $24 \mathrm{~h}$ of acclimation, $3 \mathrm{~g}$ of luminophores (100 to $160 \mu \mathrm{m}$ particle size) were evenly sprinkled across the sediment surface of each aquarium. Aquaria were then kept in darkness with circulating seawater $\left(20^{\circ} \mathrm{C}, 37 \mathrm{psu}\right)$ during the entire experiment ( $\left.48 \mathrm{~h}\right)$. The side showing the highest number of feeding cones (Maire et al. 2006) after the acclimation period was photographed under UV lights every 10 min using a digital camera (Nikon D100). Settings were adjusted for adequate fluorescent detection, and the photographic field $(17 \times 12 \mathrm{~cm})$ had a resolution superior to that of the size of luminophores ( 1 pixel $=75 \times 75 \mu \mathrm{m})$.

Images were saved in JPEG format (RGB color, 2240 $\times 1680$ pixels) and then assembled into an AVI film and processed using CVAB software (Maire et al. 2006). The water-sediment interface was first visually discriminated and manually traced with the segmented line tool in CVAB. Luminophores were then selected using an appropriate set of RGB threshold levels that differentiated target particles from the background sediment. Pixels above the threshold were added to a binary matrix where luminophore pixels were assigned a value of 1 and sediment pixels a value of 0 . Each column of pixels was then translated vertically so that the $y$-coordinate of the water-sediment interface was 0 . This flattened the water-sediment interface. After this operation, the pixel $y$-position in the image directly corresponded to its depth within the sediment (Solan et al. 2004, Maire et al. 2006). Using exactly the same set up and procedures, Maire et al. (2006) showed that the vertical profiles of luminophore concentrations recorded along the walls were similar to those classically obtained by slicing the sediment in whole aquaria. Wall effects could thus be considered limited.

Sediment mixing was first estimated by measuring luminophore particle displacement between 2 consecutive images. This surface was standardized relative to the total surface of luminophore particles to compensate for temporal changes in the amount of visible luminophore. For each image, luminophore pixels were also summed for each pixel line (i.e. depth) and vertical profiles of luminophore concentrations were generated. Vertical sediment mixing rates were then assessed using a simple biodiffusive model (Crank 1975) fitted to those vertical profiles, which resulted in the computation of biodiffusion coefficients $(\mathrm{Db})$.

Temporal changes in bivalve activity were recorded simultaneously with sediment mixing for the same sides of the 5 aquaria studied. Activity was assessed using the automated image acquisition system used during the surface sediment experiment, except that the axis of the captor lens was perpendicular to the vertical side of each studied aquarium (Fig. 1B). The photographic field $(17 \times 12 \mathrm{~cm})$ had a resolution of $230 \times 211 \mu \mathrm{m}$. Both feeding (i.e. siphon) activity and periodic oscillatory movements of the water-sediment interface were detected. Conversely to the surface sediment experiment, it was not possible to distinguish between these 2 types of activity. Total activity was therefore defined as the sum of the image areas affected by these 2 types of activity per unit of time.

Both luminophore displacements and total activities were summed and divided by the time duration since the beginning of the experiment. The so-called average cumulative luminophore displacements and average cumulative total activities were plotted together with Dbs over time, and the relationships between these variables were assessed using simple linear regression models. This procedure was carried out both on the whole aquaria and on restricted areas where only feeding activity occurred.

\section{RESULTS}

\section{Sediment surface experiment}

The position of the shell of Abra ovata did not change within the sediment after the acclimation period. During feeding periods, they extended their inhalant siphon and collected surface sediment within well-defined sub-areas. Bivalves periodically retracted their inhalant siphon, after which the siphon reemerged and began to collect sediment in a new sub-area. This resulted in a series of consecutively prospected sub-areas (Fig. 2). The first prospected subarea was always located in the immediate vicinity of the buried bivalve. Conversely, there was no clear temporal pattern in terms of: (1) distance of the subarea centers from the bivalve or (2) angular sectors of the sub-areas. Bivalves never explored the same subarea twice before the prospecting of the total area delimited by the extension of their inhalant siphon was accomplished. Surface feeding activity was between 0.04 (Bivalve 3) and $7.89 \mathrm{~cm}^{2} \mathrm{~h}^{-1}$ (Bivalve 4). For all 4 studied bivalves, there were significant temporal changes in surface feeding activity, and the greatest values were measured during the first $6 \mathrm{~h}$ of the experiments (Fig. 3). Besides surface feeding activity, 


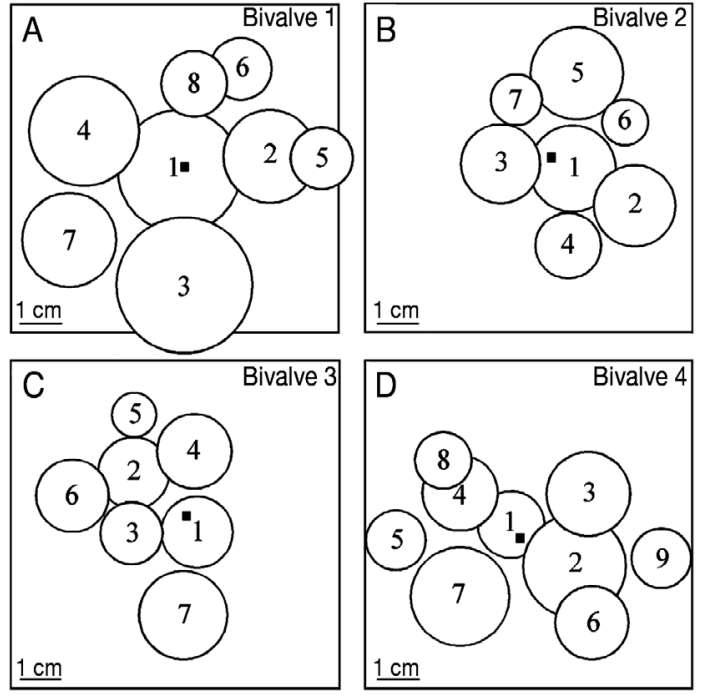

Fig. 2. Abra ovata. Sediment surface experiment. (A-D) Spatial repartitions of the sub-areas successively affected by the surface feeding activity of $A$. ovata. The center of each circle corresponds to the barycenter of each sub-area. The size of each circle is proportional to the surface of each sub-area. The number within each sub-area refers to the prospecting time sequence (i.e. Area 1 was prospected first, then Area 2, and so on). Squares indicate the positions of the bivalves within the sediment

intermittent oscillatory movements of the superficial sediment layer were also detected. They were due to foot and shell movements as later observed during sediment column experiments (see 'Results: Sediment column experiment').

For all 4 bivalves, there was only 1 area characterized by major sediment accumulation, which was located close to the buried bivalves and corresponded to 1 ejection mound, and surface feeding activity mostly created a large number of small pits in the sediment (Fig. 4). There were also some limited areas of sediment accumulation resulting from the production of fecal pellets or from surface feeding activity, and a close correspondence between the areas affected by surface feeding activity and the appearance of disturbed surface sediment. When computed over the total area studied and for the duration of the experiment, the surface sediment handling resulted either in a low net sediment accumulation (i.e. 4 and $12 \%$ of total sediment handled after $24 \mathrm{~h}$ for Bivalves 2 and 4 , respectively) or in a low net sediment excavation (i.e. 8 and $7 \%$ of total sediment handled after $24 \mathrm{~h}$ for Bivalves 1 and 3 , respectively). Surface sediment handling rates were between 2.0 (Bivalve 2) and $907.7 \mathrm{~mm}^{3} \mathrm{~h}^{-1}$ (Bivalve 4), and correlated significantly with surface feeding activity because of the peak synchronicity for these 2 parameters (Table 1 ).
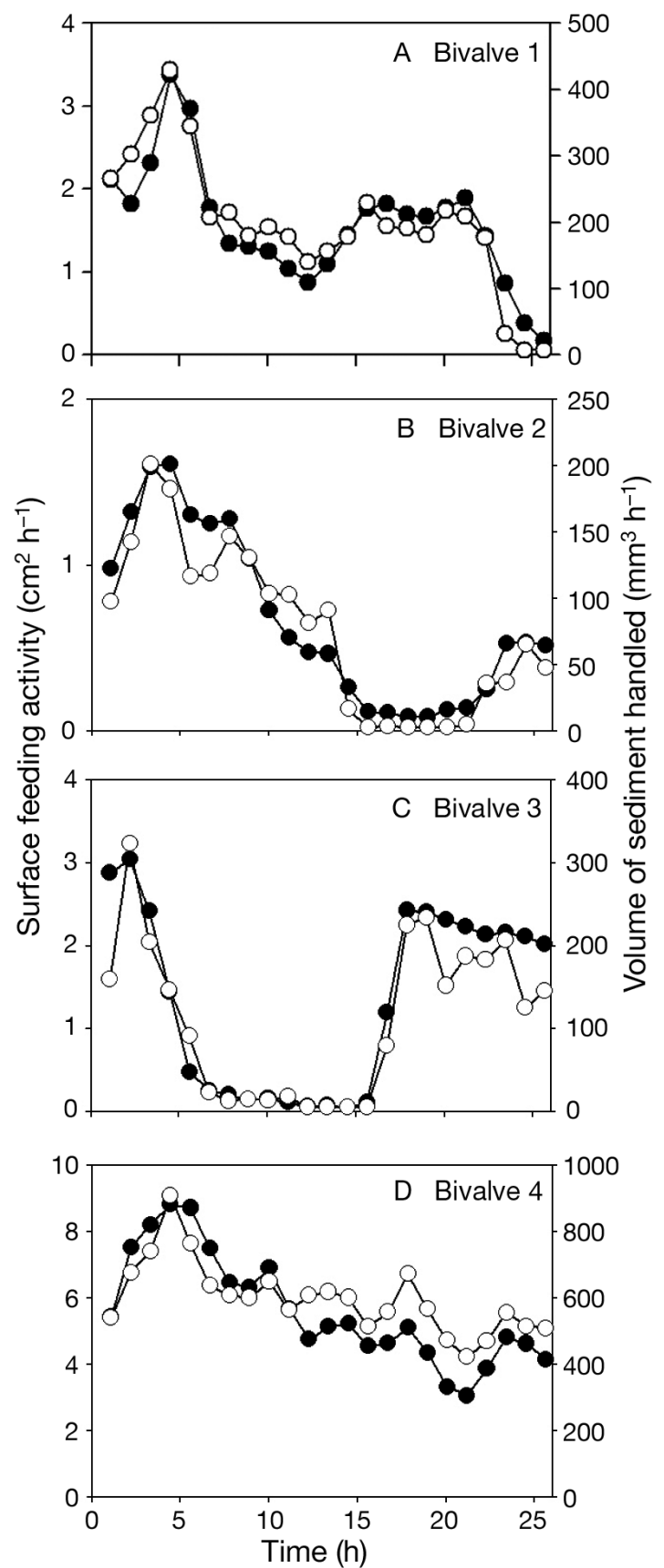

Fig. 3. Abra ovata. Sediment surface experiment. Temporal changes in surface feeding activity $(\bullet)$ and volume of sediment handled (O) by the 4 tested bivalves

\section{Sediment column experiment}

There were 2 types of activity corresponding to: (1) feeding (i.e. siphoning) activity, or (2) shell and/or foot movements. Feeding activity occurred in restricted (i.e. conical) areas and resulted in significant vertical sediment displacements, whereas shell and/or foot 

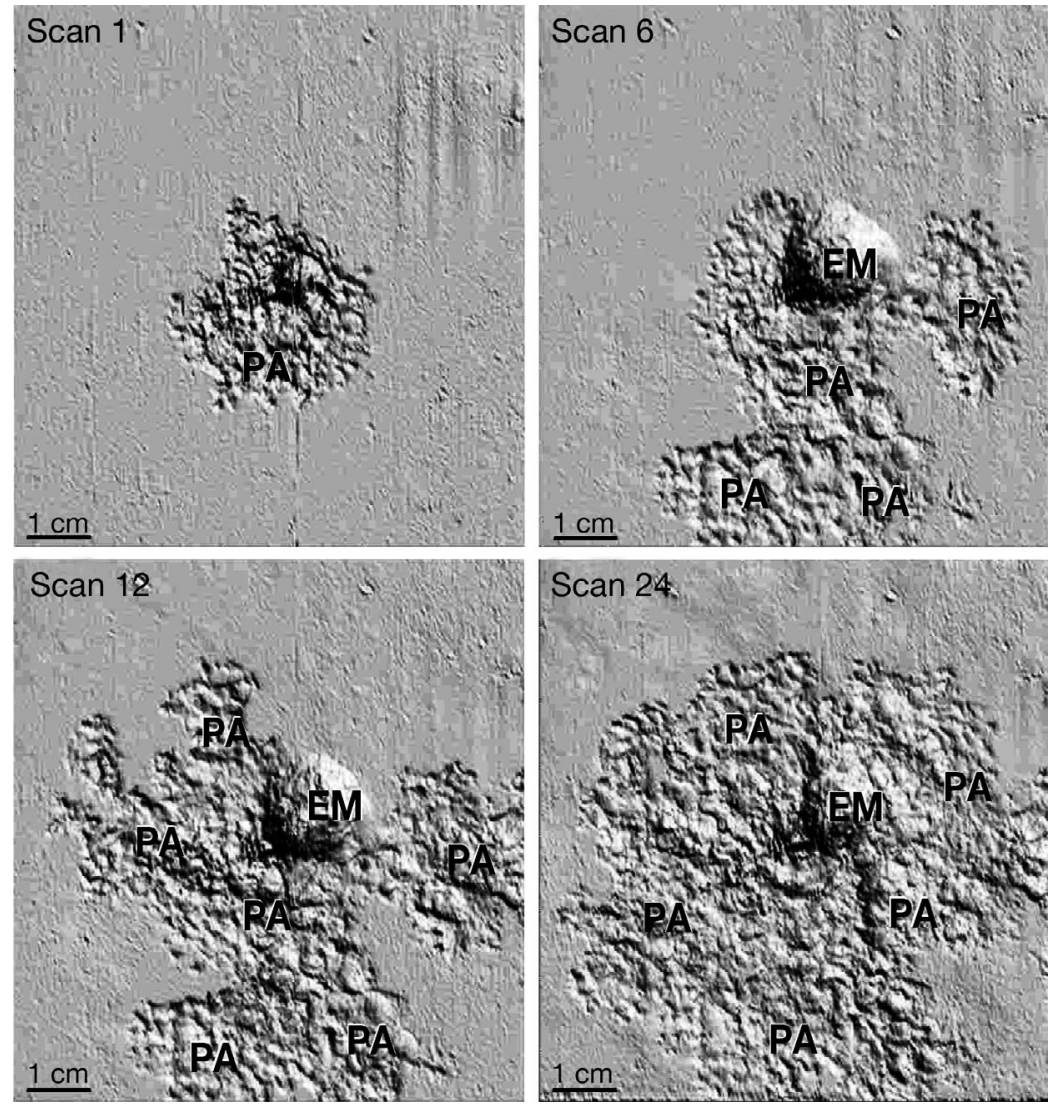

Fig. 4. Abra ovata. Sediment surface experiment. Bivalve 1. Shaded relief maps of differences in micro-topography between Scans 1, 6, 12, and 24, and Scan 0.

PA: prospected area, EM: ejection mound

Table 1. Surface sediment experiment. Determination coefficients and associated probabilities of the simple linear regression models linking surface feeding activity and the volume of sediment handled

\begin{tabular}{|llll|}
\hline Bivalve & \multicolumn{3}{c|}{$\begin{array}{c}\text { Surface feeding activity vs. } \\
\text { volume of sediment handled } \\
\end{array}$} \\
$\mathrm{n}$ & $\mathrm{r}^{2}$ & $\mathrm{p}$ \\
\hline 1 & 23 & 0.871 & $<0.001$ \\
2 & 23 & 0.906 & $<0.001$ \\
3 & 23 & 0.890 & $<0.001$ \\
4 & 23 & 0.799 & $<0.001$ \\
\hline
\end{tabular}

movements provoked short-term (less than $1 \mathrm{~min}$ ), transient uplifts of the superficial sediment layer. As indicated by the disappearance of the luminophores from the water-sediment interface, the proportion of the sediment surface affected by feeding activity was close to $100 \%$ for all 5 aquaria after $24 \mathrm{~h}$, and during that same period shell and/or foot movements affected between 14 and $25 \%$ of this surface (Table 2). Feeding activity and shell and/or foot movements occurred dur- ing between 61 and 99, and 41 and $81 \%$ of the duration of the experiment, respectively (Table 2). These 2 types of activities occurred simultaneously during 27 to $72 \%$ of the experiment duration (Table 2).

When considering the whole aquaria and experiment durations, total activities covered between $294 \times$ $10^{-5}$ and $15 \mathrm{~cm}^{2} \mathrm{~h}^{-1}$ and luminophore displacements between $234 \times 10^{-5}$ and $9.78 \mathrm{~cm}^{2} \mathrm{~h}^{-1}$. There was no significant positive correlation between total activity and luminophore displacement for 4 of 5 aquaria (Table 3). Moreover, the proportion of the variance of luminophore displacement explained by changes in total activity remained very limited $(<7.5 \%)$. Average cumulative total activities tended to increase during the first part of the experiments and then stabilized in all 5 aquaria (see Fig. 5 for Aquarium D). Average cumulative luminophore displacements showed the same temporal changes in 4 of 5 aquaria (see Fig. 5 for Aquarium D). The only exception was Aquarium A, where average cumulative luminophore displacements tended to decrease with experiment duration after only $7 \mathrm{~h}$ (data not shown). As both average total activities and average cumulative luminophore displacements were standardized relative to the experiment duration, decreases in these 2 indices indicated intervals of lower intensity for total activity and luminophore displacements. Dbs were between 1.74 and $112.35 \mathrm{~cm}^{2} \mathrm{yr}^{-1}$. Aquaria A and B showed sharp increases in Dbs at around $16 \mathrm{~h}$. Analysis of the biodiffusive model fits to vertical luminophore profiles showed that these differences corresponded to slight changes in luminophore profiles, but were amplified by the inability of the biodiffusive model to account for the presence of both surface and sub-surface peaks of luminophore concentrations (Fig. 6). Average cumulative total activities and average cumulative luminophore displacements correlated positively for 4 of 5 aquaria, and the determination coefficients of the corresponding simple linear models were higher than 0.640 for 3 of them (Table 3 ). Average cumulative total activities also correlated significantly with Dbs in 4 of 5 bivalves, but with lower determination coefficients. Average cumulative lumi- nophore displacements correlated positively with Dbs in only 3 of 5 bivalves, and their determination coefficients were all low (i.e. 
Table 2. Abra ovata. Within-sediment column experiment. Proportions of time (\% of entire experiment duration) devoted to feeding activity, foot and/or shell movements, and time during which both feeding activity and foot and/or shell movements co-occurred; and proportions (\%) of the sediment surface affected by foot and/or shell movements

\begin{tabular}{|c|c|c|c|c|}
\hline \multirow{2}{*}{ Bivalve } & \multicolumn{3}{|c|}{ Time ( $\%$ of experiment duration $)$} & \multirow{2}{*}{$\begin{array}{c}\text { Sediment surface affected } \\
\text { by movements } \\
\text { (\% of surface) }\end{array}$} \\
\hline & Feeding & Foot/shell movement & Feeding/movement co-occurrence & \\
\hline 1 & 86 & 58 & 44 & 21 \\
\hline 2 & 73 & 77 & 56 & 25 \\
\hline 3 & 73 & 69 & 61 & 22 \\
\hline 4 & 99 & 81 & 72 & 17 \\
\hline 5 & 61 & 41 & 27 & 14 \\
\hline
\end{tabular}

Table 3. Determination coefficients and associated probabilities of the simple linear regression models linking total activity (TA) and luminophore displacements (LD), cumulative total activity (CTA) and cumulative luminophore displacements (CLD), biodiffusion coefficients ( $\mathrm{Db})$ and CTA, and $\mathrm{Db}$ and CLD. Significant positive correlations are in bold

\begin{tabular}{|c|c|c|c|c|c|c|c|c|c|c|c|c|}
\hline \multirow[t]{2}{*}{ Bivalve } & \multicolumn{3}{|c|}{ LD vs. TA } & \multicolumn{3}{|c|}{ CLD vs. CTA } & \multicolumn{3}{|c|}{ Db vs. CTA } & \multicolumn{3}{|c|}{ Db vs. CLD } \\
\hline & $\mathrm{n}$ & $\mathrm{r}^{2}$ & $\mathrm{p}$ & $\mathrm{n}$ & $\mathrm{r}^{2}$ & $\mathrm{p}$ & $\mathrm{n}$ & $\mathrm{r}^{2}$ & $\mathrm{p}$ & $\mathrm{n}$ & $\mathrm{r}^{2}$ & $\mathrm{p}$ \\
\hline 1 & 198 & 0.075 & 0.001 & 271 & 0.344 & $<0.001$ & 240 & 0.639 & $<0.001$ & 240 & 0.191 & $<0.001$ \\
\hline 2 & 191 & 0.005 & 0.349 & 270 & 0.640 & $<0.001$ & 214 & 0.166 & $<0.001$ & 214 & 0.006 & 0.252 \\
\hline 3 & 235 & 0.002 & 0.460 & 268 & 0.196 & $<0.001$ & 250 & 0.075 & $<0.001$ & 250 & 0.098 & $<0.001$ \\
\hline 4 & 240 & 0.009 & 0.137 & 270 & 0.749 & $<0.001$ & 255 & 0.336 & $<0.001$ & 255 & 0.244 & $<0.001$ \\
\hline 5 & 212 & 0.004 & 0.3570 & 269 & 0.671 & $<0.001$ & 245 & 0.583 & $<0.001$ & 245 & 0.156 & $<0.001$ \\
\hline
\end{tabular}
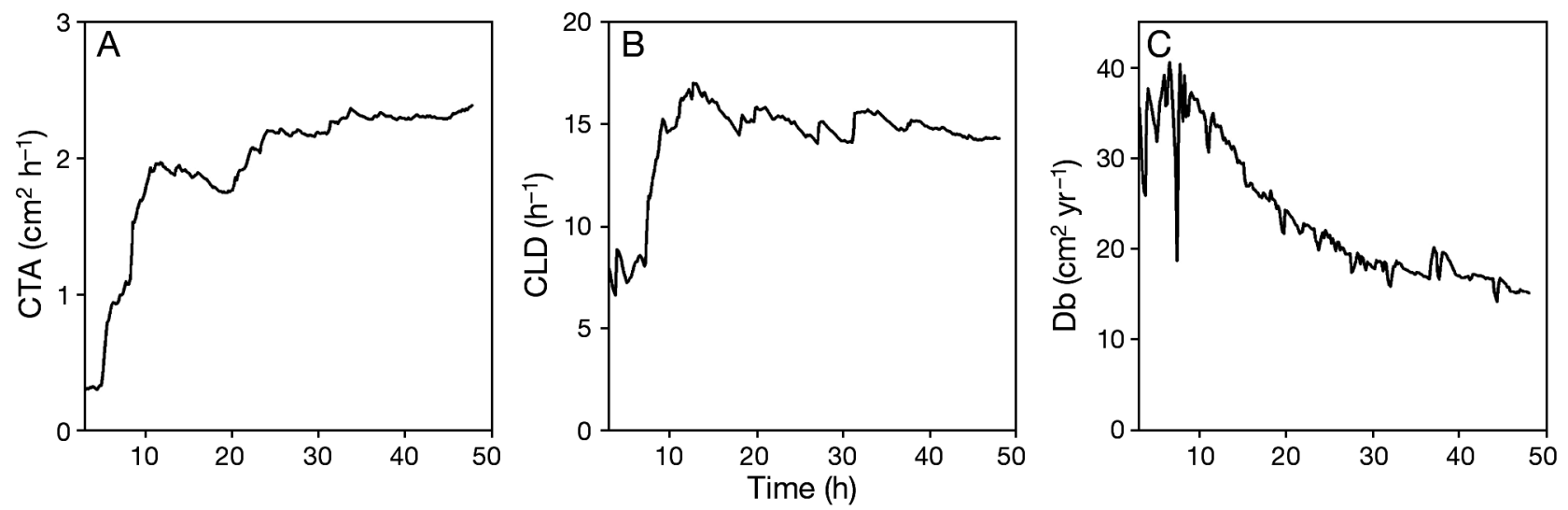

Fig. 5. Abra ovata. Sediment column experiment, Aquarium D. Temporal changes in (A) average cumulative total activity (CTA), (B) average cumulative luminophore displacement (CLD), and (C) biological diffusion coefficient (Db)

$<0.244)$. Overall, Dbs correlated better with average cumulative total activities than with average cumulative luminophore displacements, even though Dbs were computed based on the vertical distributions of the luminophores.

Fig. 7 shows an example of the observed and estimated temporal changes within a restricted area $\left(25 \mathrm{~cm}^{2}\right)$ corresponding to the conical zone where only feeding activity by an individual bivalve occurred. Feeding activity was between $594 \times 10^{-5}$ and $5.22 \mathrm{~cm}^{2}$ $\mathrm{h}^{-1}$, luminophore displacement between $168 \times 10^{-5}$ and $2.76 \mathrm{~cm}^{2} \mathrm{~h}^{-1}$, and $\mathrm{Db}$ between 5.10 and 206.86 $\mathrm{cm}^{2} \mathrm{yr}^{-1}$. Feeding activity and luminophore displacement correlated positively $\left(n=212, r^{2}=0.432, p<\right.$ 0.001). Average cumulative feeding activity, average cumulative luminophore displacements, and Dbs all had similar temporal changes and correlated positively with one another (Fig. 8). The determination coefficients of the corresponding regression models were much higher than those obtained when considering total activity in the whole Aquarium A (Table 3). Similar results were obtained for other bivalves and other restricted areas featuring only feeding activity (data not shown). 

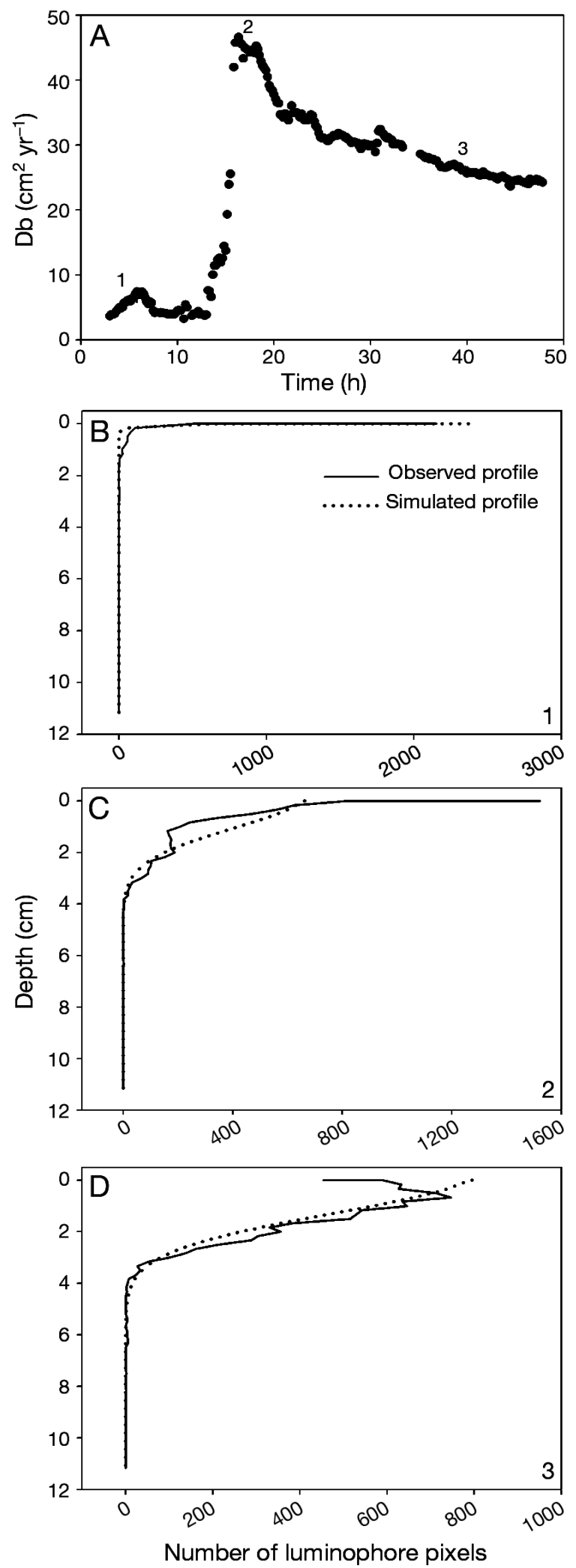

Fig. 6. Abra ovata. Sediment column experiment, Aquarium A. (A) Temporal changes in biological diffusion coefficients (Dbs) with (B-D) 3 profiles corresponding to very distinct values of this coefficient $(1,2,3$, respectively)

\section{DISCUSSION}

\section{Bivalve activity}

The image analysis techniques used during this study allowed the assessment of surface feeding activity during the sediment-surface experiment, while the monitoring carried out during the within-sediment column experiment described total activity (i.e. the sum of both the feeding activity and the movements of the shell and/or foot). Surface feeding activity corresponded to strong movements of the inhalant siphon outside the sediment, including scooping superficial sediment during feeding periods and, to a lesser extent, to movements of the exhalant siphon when expulsing fecal pellets and clouds of loose sediment. Similar activities of the 2 siphons have been reported for Yoldia limatula (Bender \& Davis 1984). We also saw transitory uplift of surface sediment overlying the bivalve. This pulse-like motion mainly corresponded to shell displacements induced by the extension of the foot (O. Maire pers. obs.).

Grémare et al. (2004) observed no marked change in the surface feeding activity of Abra ovata during $24 \mathrm{~h}$ experiments. In contrast, our experiments estimated higher surface feeding activities during the first $6 \mathrm{~h}$. A. ovata exploited the sediment in a series of distinct subareas with little overlap. The surface of the entire area prospected was limited by the reach of the inhalant siphon. One suggested hypothesis for this pattern is that it is less advantageous to forage in previously explored areas because the sediment presumably has a lower food value relative to the overlying fluffy layer (Jesus et al. 2005). This hypothesis could now be tested by comparing surface sediment biochemical characteristics in prospected and non-prospected areas, and by running complementary experiments under significant sediment transport, which could compensate changes in surface sediment characteristics (Rosenberg 1995). In addition, it would also be interesting to assess the possible potential role of pellet accumulation as a cue to depress deposit-feeding in A. ovata, as already reported for spionids (Miller \& Jumars 1986).

\section{Relationship between surface feeding activity and surface sediment handling}

Techniques of sediment micro-topography mapping have been used to account for spatial micro-heterogeneity in meiofauna distribution (Sun et al. 1993) and oxygen fluxes (Jørgensen \& Des Marais 1990, Roy et al. 2002 , 2005). These techniques were mostly based on image analysis of photographs of the sediment surface (Sun et al. 1993), and the analysis of the projection of a 
laser line onto the sediment surface (Roy et al. 2002, 2005). In this last case, micro-topography was determined by calculating the position of the laser line within successive images of the studied sediment area. The laser telemetry technique used in our experiments had a better vertical resolution (15 versus $\sim 50 \mu \mathrm{m}$ ) than that used by Roy et al. $(2002,2005)$, and moreover, it is independent of sediment configuration. In contrast, for the approach used by Roy et al. $(2002,2005)$ microtopography could not be directly assessed behind relatively high sediment mounds. This is particularly important when studying sediment reworking by Abra ovata since this bivalve creates an important ejection mound (i.e. up to $1 \mathrm{~cm}$ in height). The main drawback of our technique is the time needed to scan the whole studied area (67 min). This time period nevertheless proved appropriate for assessing surface sediment handling by A. ovata.

The individual bivalves were responsible for intense surface sediment handling. Moreover, the synchronicity between surface feeding activity and sediment handling clearly showed that the latter resulted from the former. Successive micro-topographic mappings showed several important changes in sediment microtopography: (1) a large set of small and shallow depressions over the areas prospected by the inhalant siphon, (2) 1 main ejection mound of loose sediment ejected by the exhalant siphon, and (3) a few piles of fecal pellets. Sediment excavation and accumulation were generally on the order of $5 \mathrm{~mm}$ but never exceeded $1 \mathrm{~cm}$. This is nevertheless sufficient to affect the structure of the diffusive boundary layer and thus impact biogeochemical fluxes at the water-sediment interface (Roy et al. 2002). For all studied bivalves, there was almost no change in the average level of the sediment surface during the course of the experiment. Sediment handling by Abra ovata thus did not cause a detectable change in sediment compaction.

The activities of Abra ovata are likely to affect the physical properties of the sediment in different ways. As described for many soft-bodied benthic invertebrates (Murray et al. 2002), foot activity tends to compact the sediment. Conversely, feeding activity results in the physical disruption of the superficial sediment layer due to the creation of siphon channels and to the collection of patches of superficial sediment, which later induce the ejection of loose sediment at the water-sediment interface. The production of fecal pellets by A. ovata may also contribute to the expansion of the sediment because even if the pellets have a higher density, they are also coarser than the surrounding sediment (Krantzberg 1985). The lack of temporal trend in the average level of superficial sediment thus probably reflected the balance between opposite processes resulting from the overall activity of $A$. ovata.
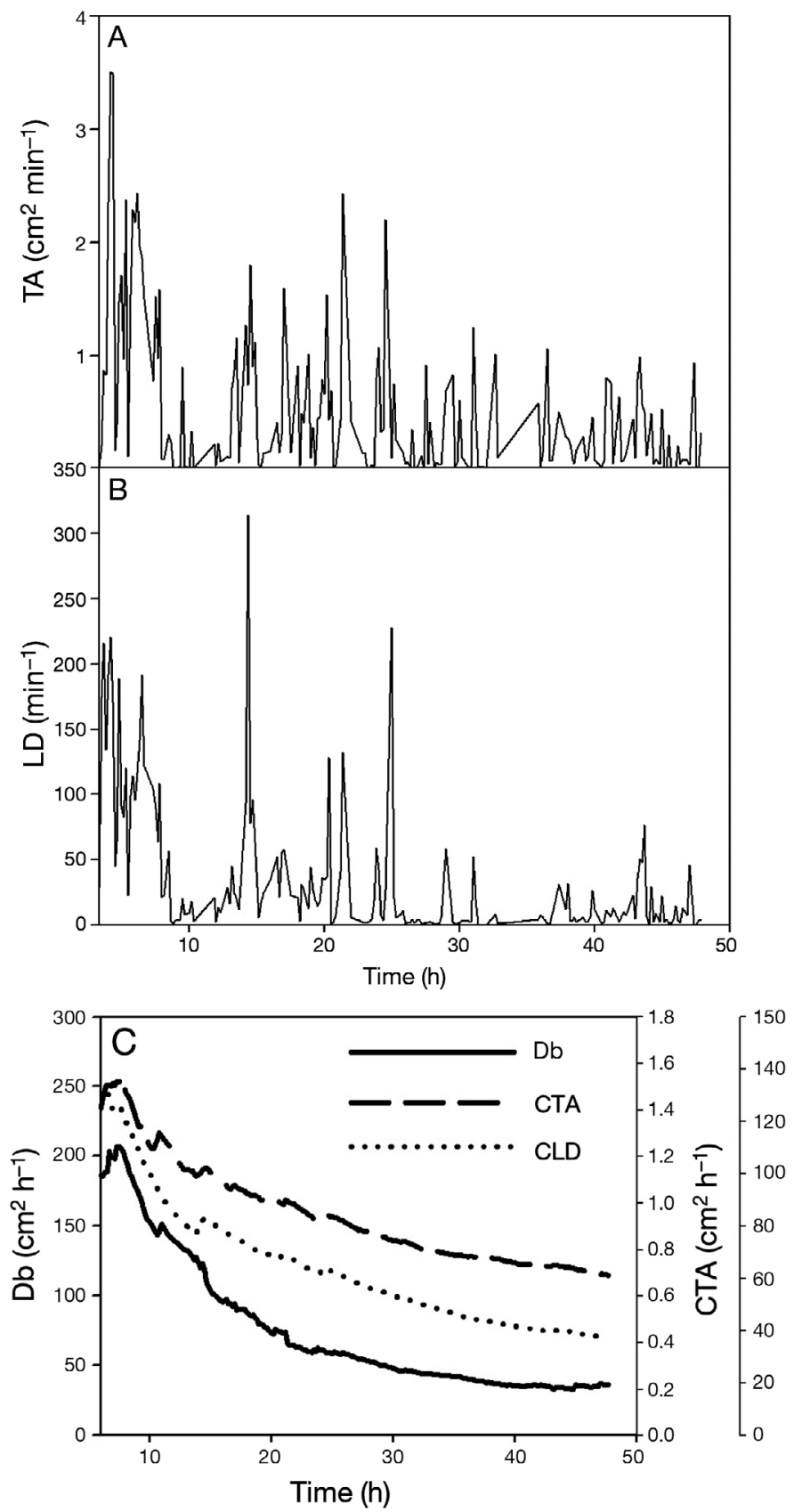

Fig. 7. Abra ovata. Sediment column experiment, Aquarium A. Temporal changes in (A) total activity (TA), (B) luminophore displacement (LD) and (C) average cumulative total activity (CTA), average cumulative luminophore displacement (CLD), and biological diffusion coefficient (Db) in an area only affected by feeding activity

\section{Relationship between bivalve activity and vertical sediment mixing}

Vertical sediment mixing is most often assessed indirectly by fitting mathematical models to vertical profiles of natural (radionuclides, chlorophyll a) or 


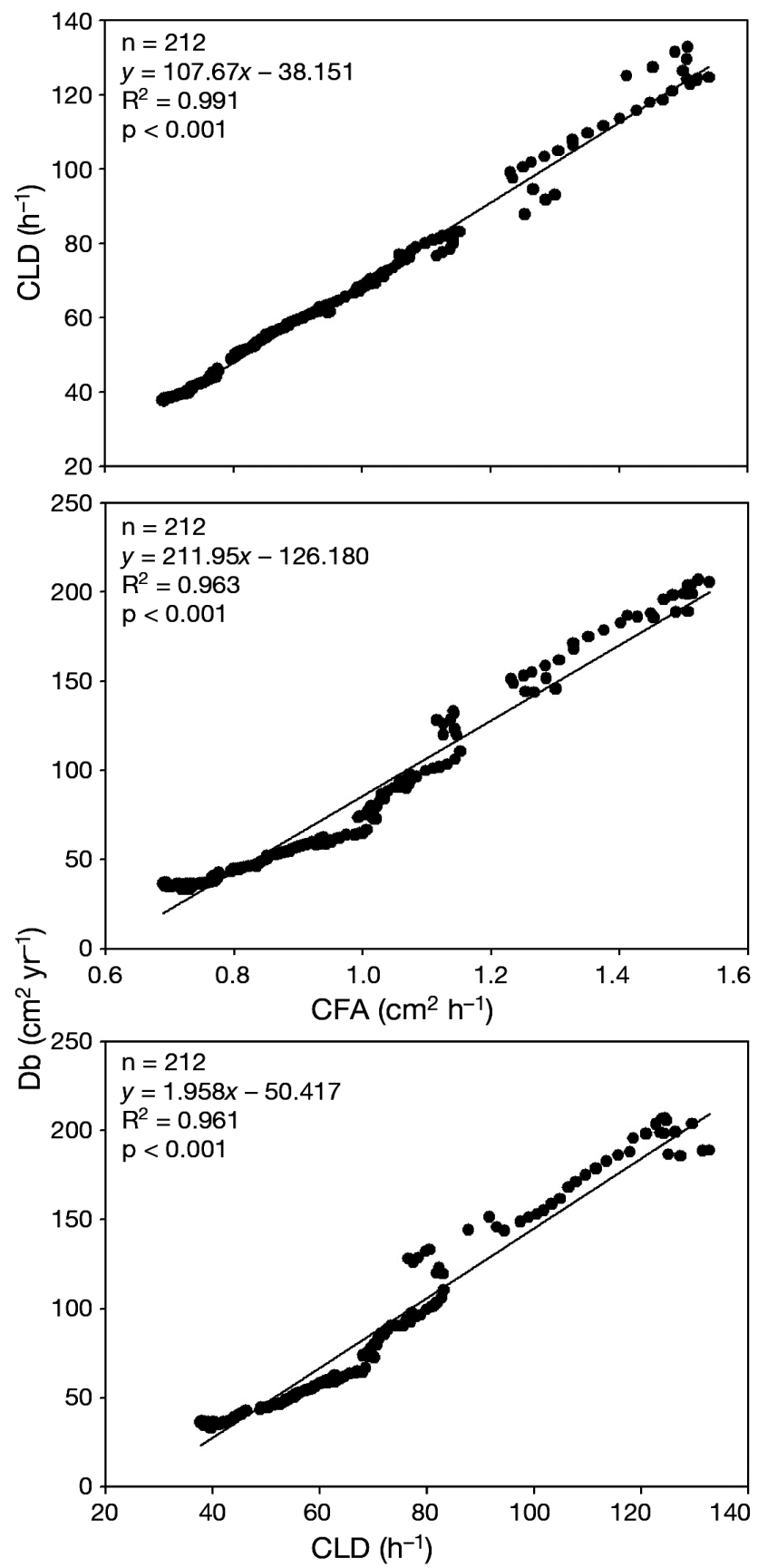

Fig. 8. Abra ovata. Sediment column experiment, Aquarium A. Relationships between (A) average cumulative feeding activity (CFA) and average cumulative luminophore displacements (CLD), (B) CFA and biological diffusion coefficients $(\mathrm{Db})$, and (C) CLD and $\mathrm{Db}$. All parameters were computed in a restricted area where only feeding activity occurred. All Db computed for this restricted area were incorporated

artificial (glass beads, metal-doped sediment, luminophores) tracers (Sharma et al. 1987, Wheatcroft 1992, Gérino et al. 1998). The most commonly used model is the biodiffusive model, which assumes that sediment particle displacements occur in a random manner over short distances (Boudreau 1986a, François et al. 1997, Meysman et al. 2003). Although the theoretical constraints (i.e. symmetry and length criteria) of this model are most often not met (Meysman et al. 2003), it has proven efficient in assessing vertical sediment mixing rates by natural communities and individual organisms and is therefore commonly used as a tool of comparison between communities and/or species (Tromp et al. 1995, Mermillod-Blondin et al. 2005). Wheatcroft et al. (1990) showed that $\mathrm{Db}$ can be decomposed in $L^{2} / 2 t$, where $L$ is a particle step length and $t$ is a rest interval between steps. A single value of $\mathrm{Db}$ can correspond to very different combinations of $L$ and $t$, and $\mathrm{Db}$ is only an imperfect description of sediment mixing. Using a non-local transport model on another data set, Maire et al. (2007) showed that: (1) in Abra ovata feeding on natural sediment, $L$ and $t$ are close to $0.2 \mathrm{~cm}$ and $7.6 \mathrm{~h}$, respectively, and (2) temporal changes in organic matter availability had little effect on $L$ but did significantly affect $t$ (which was also postulated for the positive effect of temperature on sediment mixing by Wheatcroft et al. 1990). The goal of the present study was not to further refine the computation of $L$ and $t$ in A. ovata but to link short-term temporal changes in feeding activity and vertical sediment mixing rates. As stated by Wheatcroft et al. (1990), changes in Db can reflect changes in environmental parameters and in community structure. The present within-sediment column experiment was monospecific, short-term, and carried out under constant conditions. We therefore considered that the use of $\mathrm{Db}$ was suitable to describe the relationship between feeding activity and vertical sediment mixing.

The high frequency acquisition of images of a vertical sediment section under UV light and the computation of corresponding luminophore profiles allow a dynamic view of vertical sediment mixing based on the amount of luminophores displaced (Gilbert et al. 2003). We used image analysis techniques to quantify luminophore displacements, which were then transformed in average cumulative luminophore displacements to facilitate the comparison with Dbs. When considering the whole sediment surface over the entire duration of the within-sediment column experiment, there were only weak correlations between these 2 parameters. This was partly due to the inability of the biodiffusive model to account for the occurrence of both surface and subsurface peaks of luminophores. However, these correlations became stronger when considering restricted sediment areas only affected by feeding activity, which contributed to document the quantitative relationship between feeding activity and vertical sediment mixing. This discrepancy resulted from the co-occurrence of the 2 types of activities mentioned above. Feeding activity induced 'true' vertical sedi- 
ment mixing over periods of time greater than $10 \mathrm{~min}$ (i.e. the time interval between 2 consecutive images taken under UV light). Conversely, foot and/or shell movements induced oscillatory uplifting movements of the superficial sediment layer resulting in intermittent displacements of large amounts of luminophore particles over short periods of time with no significant vertical sediment mixing over time periods longer than 10 min. In Abra ovata, high frequency measurements of luminophore displacements coupled with optical measurements of sediment mixing may therefore result in significant overestimations. Our results thus underscore the necessity of an explicit link between organism activities and sediment mixing processes even when sediment mixing rates are directly computed based on measurements of luminophore displacements (Gilbert et al. 2003). Finally, it should be underscored that foot and/or shell movements can be of high importance for processes other than sediment mixing, such as porewater fluxes.

\section{Future applications of our methodological approach}

The development of a new methodological approach coupling state of the art image analysis techniques, laser telemetry, and the use of luminophores clearly constitutes a major originality of this study. This approach can now be used for a large variety of purposes. First it must be stressed that the results of our study are based on a limited number of bivalves. Complementary experiments should now be undertaken to better quantify the relationship between feeding activity, sediment handling, and vertical sediment mixing in Abra ovata. Second, the effect of food availability on feeding activity and on vertical sediment mixing by $A$. ovata have already been studied independently (Grémare et al. 2004, Maire et al. 2006) and it would now be possible to do sediment column experiments under different regimes of food availability to assess the effect of food availability on the relationships between feeding activity and sediment mixing. Third, sediment mixing can be better parameterized by using step length $(L)$ and resting time $(t)$ than Db (Wheatcroft et al. 1990). During our study, the time interval between 2 consecutive images taken under UV light was $10 \mathrm{~min}$, which was not sufficient to allow for the detection of individual luminophore displacements, but this time interval could be decreased to attempt to assess $L$ and $t$ directly. Fourth, it would also be interesting to use our methodological approach on other organisms featuring different sediment handling and mixing types. Results could prove helpful in parameterizing both traditional (François et al. 1997, 2001) and individual-based models of sediment reworking (Boudreau et al. 2001, Choi et al. 2002).
Acknowledgements. This work was carried out within the framework of the French National Program on Coastal Environments (PNEC), within the Thematic Action MESO. O.M. was supported by a grant from the French Ministry of Education, Research, and Technology. This work was in partial fulfillment of the $\mathrm{PhD}$ thesis of O.M. at the Université Pierre et Marie Curie.

\section{LITERATURE CITED}

Aller RC (1982) The effects of macrobenthos on chemical properties of marine sediment and overlying water. In: McCall PL, Tevesz MJS (eds) Animal-sediment relations: the biogenic alteration of sediments. Topics in geobiology, Vol 2. Plenum Press, New York p 53-102

Andersen FO, Kristensen E (1988) The influence of macrofauna on estuarine benthic community metabolism: a microcosm study. Mar Biol 99:591-603

Bender K, Davis WR (1984) The effect of feeding by Yoldia limatula on bioturbation. Ophelia 23:91-100

Bianchi TS (1988) Feeding ecology of subsurface depositfeeder Leitoscoloplos fragilis Verril. 1. Mechanisms affecting particle availability on an intertidal sandflat. J Exp Mar Biol Ecol 115:79-97

Boudreau BP (1986a) Mathematics of tracer mixing in sediments: I. Spatially-dependent, diffusive mixing. Am J Sci 286:161-198

Boudreau BP (1986b) Mathematics of tracer mixing in sediments: II. Non-local mixing and biological conveyor-belt phenomena. Am J Sci 286:199-238

Boudreau BP, Imboden DM (1987) Mathematics of tracer mixing in sediments: III. The theory of nonlocal mixing within sediments. Am J Sci 287:693-719

Boudreau BP, Marinelli RL (1994) A modelling study of discontinuous biological irrigation. J Mar Res 52:947-968

Boudreau BP, Choi J, Meysman F, Francois-Carcaillet F (2001) Diffusion in a lattice-automaton model of bioturbation by small deposit feeders. J Mar Res 59:749-768

Choi J, François-Carcaillet F, Boudreau BP (2002) Latticeautomaton bioturbation simulator (LABS): implementation for small deposit feeders. Comput Geosci 28: $213-222$

Crank J (1975) The mathematics of diffusion. Oxford University Press, Oxford

Duchêne JC, Rosenberg R (2001) Marine benthic faunal activity patterns on a sediment surface assessed by video numerical tracking. Mar Ecol Prog Ser 223:113-119

François F, Poggiale JC, Durbec JP, Stora G (1997) A new approach for the modelling of sediment reworking induced by a macrobenthic community. Acta Biotheor 45: 295-319

François F, Poggiale JC, Durbec JP, Stora G (2001) A new model of bioturbation for a functional approach to sediment reworking resulting from macrobenthic communities. In: Aller JY, Woodin SA, Aller RC (eds) Organismsediment interactions. University of South Carolina Press, Columbia, SC, p 75-88

Fuller CM, Butman CA, Conway NM (1988) Periodicity in fecal pellet production by the capitellid polychaete Mediomastus ambiseta throughout the day. Ophelia 29: 83-91

Gérino M, Aller RC, Lee C, Cochran JK, Aller JY, Green MA, Hirschberg D (1998) Comparison of different tracers and methods used to quantify bioturbation during a spring bloom: 234-thorium, luminophores and chlorophyll a. Estuar Coast Shelf Sci 46:531-547 
Gilbert F, Hulth S, Stroemberg N, Ringdahl K, Poggiale JC (2003) 2D optical quantification of particle reworking activities in marine surface sediments. J Exp Mar Biol Ecol 285/286:251-263

Glud RN, Gundersen JK, Roy H, Jørgensen BB (2003) Seasonal dynamics of benthic $\mathrm{O}_{2}$ uptake in a semi-enclosed bay: importance of diffusion and faunal activity. Limnol Oceanogr 48:1265-1276

Grémare A, Duchêne JC, Rosenberg R, David E, Desmalades $M$ (2004) Feeding behaviour and functional response of Abra ovata and A. nitida compared by image analysis. Mar Ecol Prog Ser 267:195-208

Guelorget O, Mayère C (1981) Growth, biomass and production of Abra ovata in a Mediterranean lagoon, the Etang du Prevost at Palavas (Herault, France). J Rech Oceanogr 6:23-41

Hollertz K, Duchêne JC (2001) Burrowing behaviour and sediment reworking in the heart urchin Brissopsis lyrifera Forbes (Spatangoida). Mar Biol 139:951-957

Jesus B, Mendes CR, Brotas V, Paterson DM (2005) Effect of sediment type on microphytobenthos vertical distribution: modelling the productive biomass and improving ground truth measurements. J Exp Mar Biol Ecol 332:60-74

Jørgensen BB, Des Marais DJ (1990) The diffusive boundary layer of sediments: oxygen microgradients over a microbial mat. Limnol Oceanogr 35:1343-1355

Krantzberg G (1985) The influence of bioturbation on physical, chemical and biological parameters in aquatic environments: a review. Environ Pollut 39:99-122

Lindsay SM, Woodin SA (1995) Tissue loss induces switching of feeding mode in spionid polychaetes. Mar Ecol Prog Ser 125:159-169

Lindsay SM, Woodin SA (1996) Quantifying sediment disturbance by browsed spionid polychaetes: implications for competitive and adult-larval interactions. J Exp Mar Biol Ecol 196:97-112

Mahaut ML, Graf G (1987) A luminophore tracer technique for bioturbation studies. Oceanol Acta 10:323-328

Maire O, Duchêne JC, Rosenberg R, Braga de Mendonça J Jr, Grémare A (2006) Effects of food availability on sediment reworking in Abra ovata and A. nitida. Mar Ecol Prog Ser 319:135-153

Maire O, Duchêne JC, Grémare A, Malyuga VS, Meysman FJR (2007) A comparison of sediment reworking rates by the suurfacce deposit-feeding bivalve Abra ovata during summertime and wintertime, with a comparison between two models of sediment reworking. J Exp Mar Biol Ecol 343:21-36

Marinelli RL (1992) Effects of polychaetes on silicate dynamics and fluxes in sediments: importance of species, animal activity and polychaete effects on benthic diatoms. J Mar Res 50:745-779

Marinelli RL (1994) Effects of burrow ventilation on activities of a terebellid polychaete and silicate removal from sediment pore waters. Limnol Oceanogr 39:303-317

Mermillod-Blondin F, François-Carcaillet F, Rosenberg R (2005) Biodiversity of benthic invertebrates and organic

Editorial responsibility: Howard Browman (Associate Editorin-Chief), Storebø, Norway matter processing in shallow marine sediments: an experimental study. J Exp Mar Biol Ecol 315:187-209

Meysman FJR, Boudreau BP, Middelburg JJ (2003) Relations between local, nonlocal, discrete and continuous models of bioturbation. J Mar Res 61:391-410

Miller DC, Jumars PA (1986) Pellet accumulation, sediment supply, and crowding as determinants of surface depositfeeding rate in Pseudopolydora kempi japonica Imajima and Hartman (Polychaeta: Spionidae). J Exp Mar Biol Ecol 99:1-17

Murray JMH, Meadows A, Meadows PS (2002) Biogeomorphological implications of microscale interactions between sediment geotechnics and marine benthos: a review. Geomorphology 47:15-30

Rhoads DC (1974) Organism-sediment relations on the muddy sea floor. Oceanogr Mar Biol Annu Rev 12: 263-300

Rice DL (1986) Early diagenesis in bioadvective sediments: relationships between the diagenesis of beryllium-7, sediment reworking rates, and the abundance of conveyorbelt deposit-feeders. J Mar Res 44:149-184

Rosenberg R (1995) Benthic marine fauna structured by hydrodynamic processes and food availability. Neth J Sea Res 34:303-317

Roy H, Huettel M, Jørgensen BB (2002) The role of smallscale sediment topography for oxygen flux across the diffusive boundary layer. Limnol Oceanogr 47:837-847

Roy H, Huettel M, Jørgensen BB (2005) The influence of topography on the functional exchange surface of marine soft sediments, assessed from sediment topography measured in situ. Limnol Oceanogr 50:106-112

Sharma P, Gardner LR, Moore WS, Bollinger MS (1987) Sedimentation and bioturbation in a salt marsh as revealed by ${ }^{210} \mathrm{~Pb},{ }^{137} \mathrm{Cs}$, and ${ }^{7} \mathrm{Be}$ studies. Limnol Oceanogr 32:313-326

Solan M, Wigham BD, Hudson IR, Kennedy R, Coulon $\mathrm{CH}$, Norling K, Nilsson HC, Rosenberg R (2004) In situ quantification of bioturbation using time-lapse fluorescent sediment profile imaging (f-SPI), luminophore tracers and model simulation. Mar Ecol Prog Ser 271:1-12

Sun B, Fleeger JW, Carney RS (1993) Sediment microtopography and the small-scale spatial distribution of meiofauna. J Exp Mar Biol Ecol 167:73-90

Tromp TK, Van Cappellen P, Key RM (1995) A global model for the early diagenesis of organic carbon and organic phosphorus in marine sediments. Geochim Cosmochim Acta 59:1259-1284

Waldbusser GG, Marinelli RL (2006) Macrofaunal modification of porewater advection: role of species function, species interaction, and kinetics. Mar Ecol Prog Ser 311: $217-231$

Wheatcroft RA (1992) Experimental tests for particle sizedependent bioturbation in the deep ocean. Limnol Oceanogr 37:90-104

Wheatcroft RA, Jumars PA, Smith CR, Nowell ARM (1990) A mechanistic view of the particulate biodiffusion coefficient: step lengths, rest periods and transport directions. J Mar Res 48:177-207

Submitted: March 22, 2007; Accepted: July 6, 2007

Proofs received from author(s): November 22, 2007 